\title{
UM "RAIO-X" DA PRODUÇÃO DO CONHECIMENTO SOBRE EDUCAÇÃO FÍSICA ESCOLAR: ANÁLISE DE PERIÓDICOS DE 2006 A 2012
}

\author{
AN "X-RAY" OF KNOWLEDGE PRODUCTION ON SCHOOL PHYSICAL \\ EDUCATION: ANALYSIS OF JOURNALS PUBLISHED FROM 2006 TO 2012
}

\author{
UNA RADIOGRAFÍA DE LA PRODUCCIÓN DE CONOCIMIENTO SOBRE \\ EDUCACIÓN FÍSICA ESCOLAR: ANÁLISIS DE PUBLICACIONES CIENTIFICAS \\ ENTRE 2006 Y 2012
}

\begin{abstract}
Ingrid Dittrich Wiggers ${ }^{*}$ Nadson Santana Reis Letícia Rodrigues Teixeira e Silva*, Marisa Mello de Lima*, Tayanne da Costa Freitas*, Thainá Rodrigues de Moura Praça*, Mayrhon José Abrantes Farias*
\end{abstract}

Palavras-chave Bibliometria. Artigo de revista. Publicações periódicas como assunto.

\begin{abstract}
Resumo: 0 objetivo do trabalho é analisar tendências da pesquisa em Educação Física Escolar no Brasil. Desenvolveu-se revisão sistemática em periódicos nacionais, de 2006 a 2012. A produção dessa área representa apenas $16,20 \%$ do total de artigos publicados. Entre os delineamentos, pesquisas bibliográficas e de campo se destacaram. Os estudos de enfoque diagnóstico se sobressaíram. Observa-se ainda uma tendência de crescimento em estudos de intervenção pedagógica, tal como no cenário internacional. Considerando a relevância social da Educação Física Escolar, faz-se necessário fomentar políticas de pesquisa e pós-graduação que atendam às especificidades da área.
\end{abstract}

Keywords:

Bibliometric. Journal article. Journal publications as subject.

Palabras clave Bibliometría. Artículo de revista. Publicaciones de revistas científicas como tema.
Abstract: This study aims at assessing research trends on school physical education in Brazil. A systematic review was conducted in national journals published from 2006 to 2012. Production in the field represents only $16.20 \%$ of the total of articles published, and bibliographic and field research stood out. Diagnostic studies were prominent. There is also an increasing trend in pedagogical intervention studies, as well as in the international scenario. Considering the social relevance of school Physical Education, it is necessary to foster research and graduate policies that meet the specifics of that field.

Resumen: El objetivo de este trabajo es analizar tendencias en la investigación en Educación Física escolar en Brasil. Fue realizada una revisión sistemática en publicaciones científicas nacionales entre 2006 y 2012. La producción en el área representa sólo un $16,20 \%$ del total de artículos publicados. Destacaron las investigaciones bibliográficas y de campo. Los estudios con enfoque diagnóstico también tuvieron destaque. Además, se observa una tendencia de crecimiento en estudios de intervención pedagógica, tal como ocurre en el escenario internacional. Considerando la importancia social de la Educación Física escolar, se hace necesario fomentar políticas de investigación y posgrado centradas en las especificidades del área.
*Universidade de Brasília. Brasília, DF, Brasil.

E-mail: ingridwiggers@gmail.com

Recebido em: 28-09-2014

Aprovado em: 05-06-2015

(c) (i) (2) Licence 


\section{INTRODUÇÃOO}

Fazer um "raio-X" da produção do conhecimento sobre Educação Física Escolar constitui tarefa ousada e desafiante. Não apenas pela abrangência desse campo, que é permeado por práticas educativas que se desenvolvem nas escolas, políticas públicas, formação de professores e produção do conhecimento, mas, sobretudo, pela complexidade para apanhá-lo em processo. Logo, buscar uma compreensão explicativa da Educação Física Escolar supõe tratá-la à luz de seu enredo - o que foi, o que está sendo e o que tende a ser -, dada sua construção histórica e consolidação como campo acadêmico-científico.

No início da década de 1980, a Educação Física brasileira atravessou um processo de reflexão das práticas no ambiente escolar, bem como do perfil acadêmico na esfera da produção do conhecimento. Esse ficou conhecido como "movimento renovador", a partir do qual se anunciaram novas perspectivas teórico-metodológicas de trato pedagógico, coerentes com um projeto político e educacional de teor críico (BRACHT, 1999). Por conseguinte, a Educação Física, a despeito de sua tradicional ligação com a influência médica, buscou ancorar-se em referências de outras disciplinas, especialmente as do campo das Ciências Humanas e Sociais. Trata-se de uma "[...] mudança de tal magnitude que é possível comparar esse fenômeno a um ponto de inflexão na qual a trajetória da EF faz uma quebra definitiva com sua tradição legitimadora" (GONZÁLEZ; FENSTERSEIFER, 2009, p. 10).

No Brasil, a produção do conhecimento está, majoritariamente, ligada aos programas de pós-graduação. Portanto, situar as pesquisas em Educação Física Escolar implica entendêlas como resultantes de processos abrangentes que marcam o fazer científico, bem como de movimentos mais específicos que afetam a área, especialmente suas formas de conhecer. Conforme mencionado, a década de 1980 e o movimento renovador são imprescindíveis para a edificcação do espaço acadêmico-científico da área. Todavia, sua constituição como campo de produção de conhecimento está efetivamente ligada à política científica da década de 1990. Nesse período, buscou-se elevar o status científico da Educação Física, a fim de justificar sua presença nas universidades (TANI, 1996). Esse processo gerou profundas modificações para 0 campo, tendo sido desencadeado, originalmente, nos Estados Unidos (HENRY, 1964; 1978 apud Antunes et al., 2005).

Tais alterações afetaram a pesquisa, a preparação profissional e também a pós-graduação. 0 resultado desse investimento foi um avanço acadêmico-científico que pode ser constatado, entre outros indicadores, pelo aumento expressivo "[...] no volume de estudos conduzidos, no número de periódicos especializados, na quantidade de eventos científicos realizados, no número de publicações [...]" (TANI, 1996, p. 19). Conquanto, segundo o autor, esses avanços não desdobraram na qualificação da prática profissional.

Os programas de pós-graduação e, com eles, a produção científica, se organizaram em três grandes áreas de concentração: biodinâmica - orientada pelas ciências naturais -, sociocultural e pedagógica, estas duas conduzidas pelas Ciências Humanas e Sociais (MANOEL; CARVALHO, 2011). Desse modo, a Educação Física evidencia em seu campo disciplinar uma disputa interna entre subáreas, que defendem, cada uma a seu modo, abordagens diferentes para a pesquisa, tal como destacou Bourdieu (1990) para as Ciências Sociais.

A afirmação da Educação Física como área, ainda hoje, supõe debate em torno de questões polêmicas como legitimidade acadêmico-científica e reconhecimento como prática 
social (MANOEL; CARVALHO, 2011). Sobretudo, se coloca o desafio da reinvenção e construção de um novo referencial para a Educação Física na escola. Tal empreendimento depende de um esforço colaborativo entre pesquisadores, pois a produção do conhecimento não é um projeto isolado. "É uma construção coletiva da comunidade científica, um processo continuado de busca, no qual cada nova investigação se insere, complementando ou contestando contribuições anteriores dadas ao estudo do tema" (MAZZOTI; GEWANDSZNADJER, 1999, p. 180). Nessa direção, a revista Movimento, desde que foi lançada, em 1994, vem se destacando entre os periódicos brasileiros da área de Educação Física, o que pode ser ilustrado pelo elevado nível que atingiu no sistema de avaliação Qualis da Capes. Além disso, foi evidenciada como um dos três veículos que mais publicaram fontes sobre a Educação Física Escolar, no período de $1980 \mathrm{a}$ 2010 (BRACHT et al., 2011).

Diante do interesse pelo quadro anteriormente assinalado, o objetivo do trabalho é identificar e analisar as principais tendências da pesquisa em Educação Física Escolar, por meio de revisão de literatura em oito periódicos da área, de 2006 a 2012. Para realizar a análise foram selecionados aspectos que contextualizam a produção, bem como outros relacionados à abordagem metodológica e ao enfoque temático. A atualidade e a pertinência desse tipo de estudo residem na constituição de um quadro panorâmico sobre um campo de interesse, identificando tendências e limites, oferecendo, desse modo, um diagnóstico para nortear seu desenvolvimento (LUNA, 1997).

\section{DELINEAMENTO}

Nas trilhas da pesquisa em Educação Física Escolar empreendeu-se um estudo de revisão sistemática, que combina aspectos quantitativos e qualitativos de análise. Trata-se de um delineamento que busca selecionar, caracterizar e avaliar a produção científica de uma determinada área do conhecimento (SAMPAIO; MANCINI, 2007). Esse não se restringe a agregar informações, mas também acompanhar o curso científico de um campo de pesquisa, em um período específico (GOMES; CAMINHA, 2014).

Os trabalhos de revisão de literatura são destinados à divulgação e comunicação científica, e por essa razão estão sujeitos a critérios. Na preparação dos trabalhos selecionaram-se as revistas que seriam utilizadas como base de dados. A seleção partiu de sua representatividade como canal de divulgação da produção do conhecimento em Educação Física. A escolha se justifica ainda pelo fato de apresentarem perspectivas diferentes do campo de conhecimento e intervenção da Educação Física, vinculando-se tanto à visão pedagógica e social, quanto à perspectiva biodinâmica. Além disso, trata-se de revistas de grande circulação no campo e indexadas à base de dados da Capes nos extratos $\mathrm{A}$ e B. Não obstante, o sistema de seleção dos periódicos também seguiu critérios definidos anteriormente por Bracht et al. (2011; 2012), que desconsideraram periódicos de abordagens temáticas específicas, que restringem as publicações a subáreas da Educação Física. Foram elencadas oito revistas: Motrivivência, Motriz, Movimento, Pensar a Prática, Revista Brasileira de Ciência e Movimento (RBCM), Revista Brasileira de Ciências do Esporte (RBCE), Revista Brasileira de Educação Física e Esporte (RBEFE) e Revista da Educação Física/UEM (REF/UEM).

No início dos trabalhos, desenvolveram-se reuniões de discussão dos procedimentos empreendidos na seleção dos estudos, aquilo que em Gomes e Caminha (2014) corresponde 
à "reunião de consenso" entre os autores. Levando em conta que o objetivo deste trabalho é constituir um quadro panorâmico, optou-se por associar os estudos a um conceito abrangente de Educação Física Escolar. Foram reunidos artigos que tematizaram questões de ordem filosófica e conceitual, bem como aqueles de cunho didático, obtendo-se, desse modo, um corpus ampliado de fontes.

Ainda nessa etapa, apontaram-se critérios de inclusão, ou seja, artigos relacionados à Educação Física Escolar publicados nas citadas revistas e disponíveis na internet. 0 recorte temporal abrangeu o período de 2006 a 2012, compreendendo, portanto, sete anos, o que ultrapassa o recomendado por Luna (1997) para retroceder no tempo em trabalhos de revisão. Adicionalmente, sumariaram-se os procedimentos de seleção e triagem dos artigos, que envolveu leitura dos títulos, dos resumos e das palavras-chave.

Após a seleção das fontes, procedeu-se à organização dos dados e análise do material coletado. Para realizar a análise foram considerados aspectos como volume, financiamento, sexo dos autores e distribuição regional, buscando evidenciar contornos mais aparentes da literatura sobre Educação Física Escolar. Além desses, foram privilegiados elementos relacionados à abordagem metodológica e ao enfoque temático, pretendendo, assim, uma visão mais aprofundada. $A$ análise também envolveu a leitura completa dos textos, dando-se atenção aos aspectos a serem interpretados. Ao longo do processo foi feita, oportunamente, revisão do primeiro enquadramento dos artigos.

Para o sexo dos autores e a distribuição regional, a análise foi circunscrita ao autor principal, que foi assim considerado levando-se em conta a liderança institucional, evidenciada por meio da coordenação de grupos de pesquisa, atuação em programas de pós-graduação e exercício de ensino superior. Para isso foi necessário consultar a plataforma Lattes de currículo. Em algumas situações, os artigos apresentaram autores que exerciam liderança equivalente e, para esses casos, utilizou-se como critério a ordem de apresentação dos autores no artigo. Acredita-se que, desse modo, a análise dos autores obteve resultados satisfatórios, pois os líderes institucionais tendem a marcar a autoria da produção da área de forma mais duradoura.

Em relação aos tipos de pesquisa e aos temas enfocados, a análise foi desenvolvida a partir de um confronto entre as fontes examinadas e classificações já desenvolvidas pela literatura. Para os tipos de pesquisa utilizaram-se como referência básica as classificações propostas por Gil (2008), com adaptações necessárias para se dar relevo às características das fontes. Ressalve-se que a categoria "pesquisa bibliográfica" agregou artigos de revisão, ensaios e pesquisa bibliográfica de caráter mais sistematizado.

Para a análise dos enfoques temáticos, o estudo seguiu as categorias e subcategorias de Bracht et al. (2011; 2012), mas com adaptações pertinentes às fontes literárias do período investigado. Os artigos foram distribuídos em três grupos: "fundamentação", "intervenção" e "diagnóstico". Os artigos de fundamentação referem-se àqueles que dão ênfase a elaborações teóricas do campo da Educação Física Escolar. Nessa categoria substituiu-se a subcategoria "inclusão" por "temas emergentes", pois a primeira reuniu um número insignificante de trabalhos. Em contrapartida, identificou-se nas fontes um conjunto de temas novos, fruto de questões emergentes.

Estudos que oferecem descrições e panoramas relativos a temáticas da Educação

Física Escolar, por intermédio de pesquisa empírica, foram associados à categoria diagnóstico. 
Diferentemente de Bracht et al. (2011), nesta inseriu-se a subcategoria "diagnósticos relativos ao desenvolvimento motor/cineantropometria", reunindo artigos que pretendiam conhecer, por exemplo, as condições e o comportamento físico-motor de escolares. Por sua vez, a ênfase na intervenção se caracteriza por estudos que enfrentaram a ação pedagógica na escola propriamente dita. Esta categoria permaneceu inalterada em relação ao proposto por Bracht et al. (2011; 2012).

\section{MAPEAMENTO DA PRODUÇÃO}

Como resultado dos procedimentos anteriormente descritos, produziu-se um conjunto de 428 artigos que se situam no campo da Educação Física Escolar, publicados entre 2006 e 2012. Considerando o total de 2.632 artigos veiculados pelas revistas selecionadas no período, esse volume corresponde a apenas 16,20\%, conforme a Tabela 1.

Tabela 1 - Produção em Educação Física Escolar nas revistas

\begin{tabular}{lccccc}
\hline Revistas & $\begin{array}{c}\text { Total de } \\
\text { artigos }\end{array}$ & $\begin{array}{c}\text { Artigos da } \\
\text { EFE* }^{*}\end{array}$ & $\begin{array}{c}\text { \% em relação } \\
\text { à produção } \\
\text { da revista }\end{array}$ & $\begin{array}{c}\text { \% na participação da } \\
\text { revista na produção } \\
\text { da EFE* }\end{array}$ & $\begin{array}{c}\text { \% do peso da EFE* } \\
\text { na produção total } \\
\text { (2.632 artigos) }\end{array}$ \\
\hline Movimento & 324 & 77 & 23,80 & 18,00 & 2,92 \\
Pensar a Prática & 264 & 76 & 28,80 & 17,80 & 2,89 \\
Motriz & 488 & 66 & 13,50 & 15,20 & 2,50 \\
RBCE & 340 & 61 & 17,90 & 14,30 & 2,32 \\
Motrivivência & 199 & 56 & 28,10 & 13,10 & 2,13 \\
REF/UEM & 349 & 37 & 10,60 & 8,70 & 1,41 \\
RBEFE & 295 & 28 & 9,50 & 6,60 & 1,06 \\
RBCM & 373 & 27 & 7,20 & 6,30 & 1,03 \\
\hline TOTAL & 2632 & 428 & 16,20 & 100 & 16,20 \\
\hline
\end{tabular}

${ }^{\star} E F E$ : Educação Física Escolar.

Fonte: Os autores.

Observou-se ainda que a produção saiu de 7,30\% em 2006 para 17,10\% em 2008, perfazendo um total de 10 pontos percentuais de crescimento. De 2008 até 2012 a produção se estabilizou em torno de $15 \%$, voltando a subir no final do período avaliado para $18,20 \%$. Apesar do pequeno volume da produção do conhecimento que se refere ao recorte da Educação Física Escolar, interessante notar, conforme ilustrado no Gráfico 1, uma ascensão dessa produção, no período de 2006 a 2008, mantendo-se em alta relativamente estável até 2012.

Gráfico 1 - Produção em Educação Física Escolar nos anos de 2006 a 2012

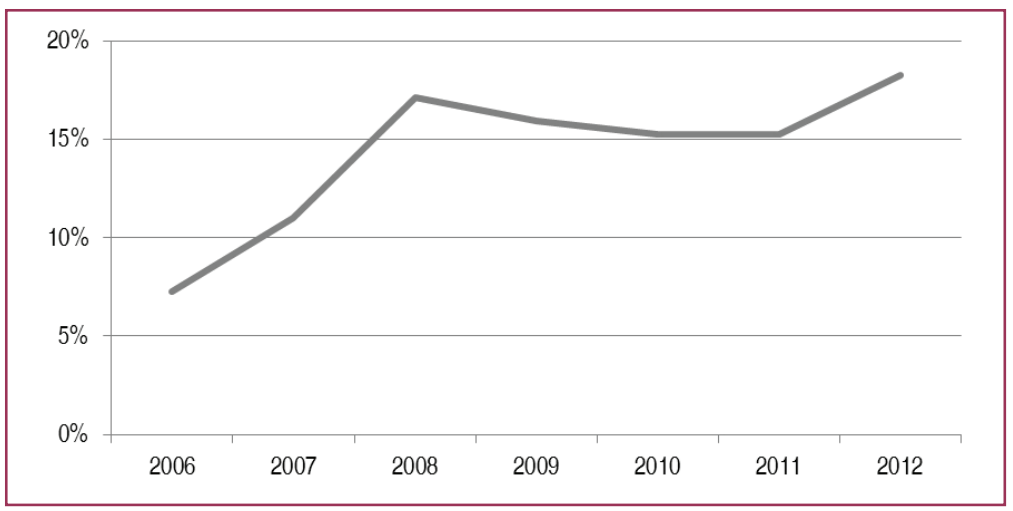

Fonte: Os autores 
Quanto ao financiamento das pesquisas, seja por capital/custeio ou concessão de bolsas, observa-se que apenas $11,21 \%$ dos artigos publicados é produto de fomento, de acordo com a distribuição por agências, indicada no Gráfico 2. Saliente-se que as agências e órgãos federais e estaduais de fomento apoiaram $79,16 \%$ do total de pesquisas financiadas.

Gráfico 2 - Agências financiadoras das pesquisas em Educação Física Escolar

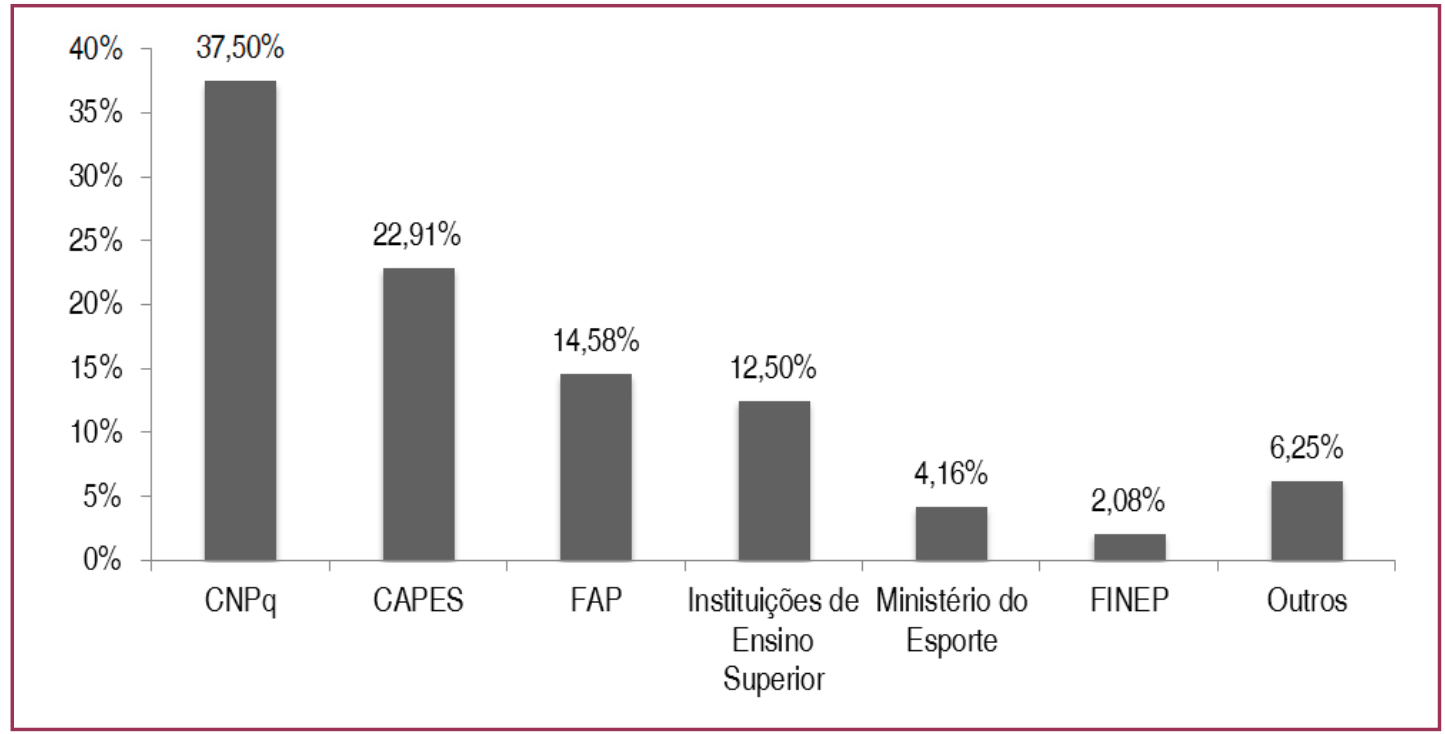

Fonte: Os autores.

Considerando o sexo dos autores principais dos artigos analisados, o Gráfico 3 denota que $55,84 \%$ das pesquisas foram coordenadas por homens, contra $44,16 \%$ por mulheres.

Gráfico 3 - Proporção de homens e mulheres na pesquisa em Educação Física Escolar

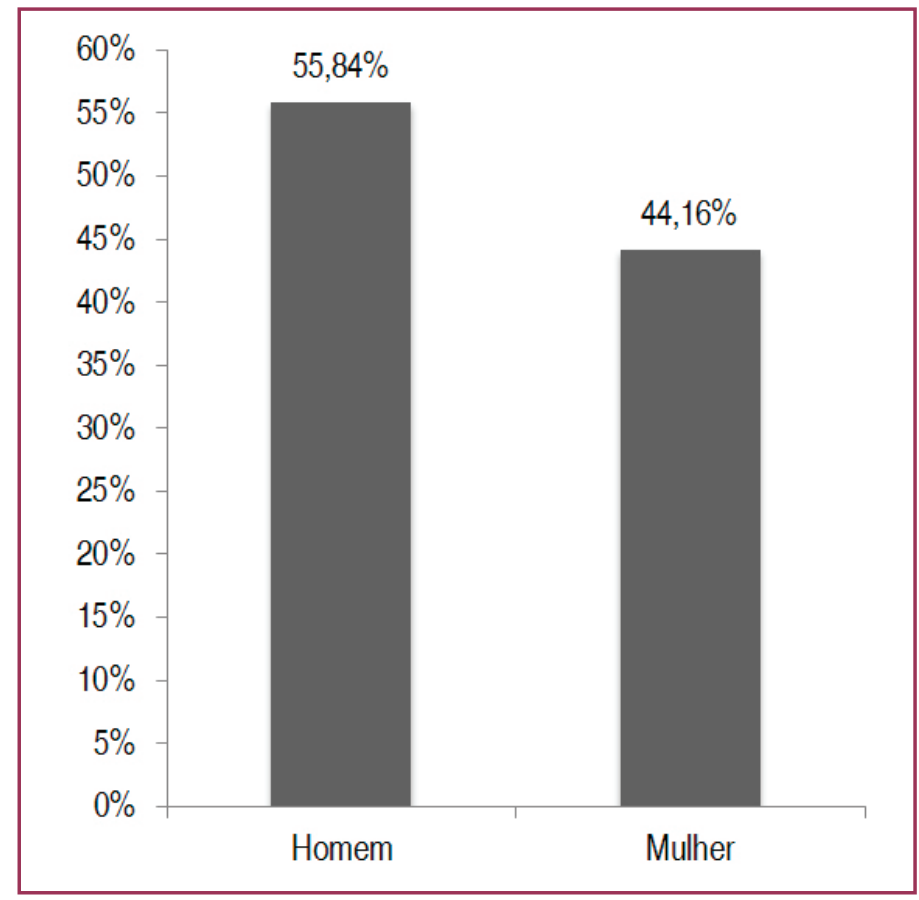

Fonte: Os autores.

Quanto à distribuição da produção por regiões brasileiras, verifica-se concentração no Sudeste e Sul, que respondem por mais de $80 \%$ das pesquisas publicadas. A Tabela 2 
evidencia a discrepância da distribuição regional das pesquisas em Educação Física Escolar no país. Cabe sublinhar a difusão da produção das regiões Sudeste e Sul que, majoritariamente, concentra-se nas revistas Motriz e Movimento, respectivamente. Essas estão sediadas na Universidade Estadual Paulista (UNESP), localizada na região Sudeste, e na Universidade Federal do Rio Grande do Sul (UFRGS), localizada na região Sul. Ambas são avaliadas como A2 no sistema Qualis, que representa o maior nível entre as revistas consultadas.

Tabela 2 - Distribuição dos artigos por região

\begin{tabular}{lcccccc}
\hline Revistas & $\begin{array}{c}\% \text { do } \\
\text { Sudeste }\end{array}$ & \% do Sul & $\begin{array}{c}\% \text { do } \\
\text { Nordeste }\end{array}$ & $\begin{array}{c}\% \text { do } \\
\text { Centro-Oeste }\end{array}$ & \% do Norte & $\begin{array}{c}\% \text { de } \\
\text { internacional }\end{array}$ \\
\hline Motrivivência & 27,78 & 48,15 & 11,11 & $12,50 \%$ & 0,00 & 0,00 \\
Motriz & 72,73 & 15,15 & 4,55 & 4,55 & 1,52 & 0,00 \\
Movimento & 31,17 & 59,74 & 1,30 & 1,30 & 0,00 & 6,49 \\
Pensar a Prática & 38,16 & 36,84 & 9,21 & 10,53 & 1,32 & 3,95 \\
RBCM & 29,63 & 51,85 & 7,41 & 7,41 & 0,00 & 3,70 \\
RBCE & 45,90 & 36,07 & 9,84 & 1,64 & 1,64 & 4,92 \\
RBEFE & 53,57 & 46,43 & 0,00 & 0,00 & 0,00 & 0,00 \\
REF/UEM & 45,95 & 43,24 & 5,41 & 2,70 & 0,00 & 2,70 \\
\hline TOTAL & 42,99 & $\mathbf{4 1 , 1 2}$ & $\mathbf{6 , 7 8}$ & $\mathbf{5 , 3 7}$ & $\mathbf{0 , 7 0}$ & $\mathbf{3 , 0 4}$ \\
\hline
\end{tabular}

Fonte: Os autores.

Almejando compreender a lógica do processo de produção do conhecimento da área de Educação Física Escolar, analisaram-se os tipos de pesquisa que delinearam os estudos analisados. O Gráfico 4 evidencia que 30,60\% se caracterizam como bibliográficas e 28,27\% como pesquisa de campo, o que indica as atuais tendências da metodologia de pesquisa em Educação Física Escolar. O Gráfico 4 ilustra também que a pesquisa-ação e a pesquisa experimental são as formas menos utilizadas na produção de conhecimento do campo da Educação Física Escolar.

Gráfico 4. - Tipos de pesquisas

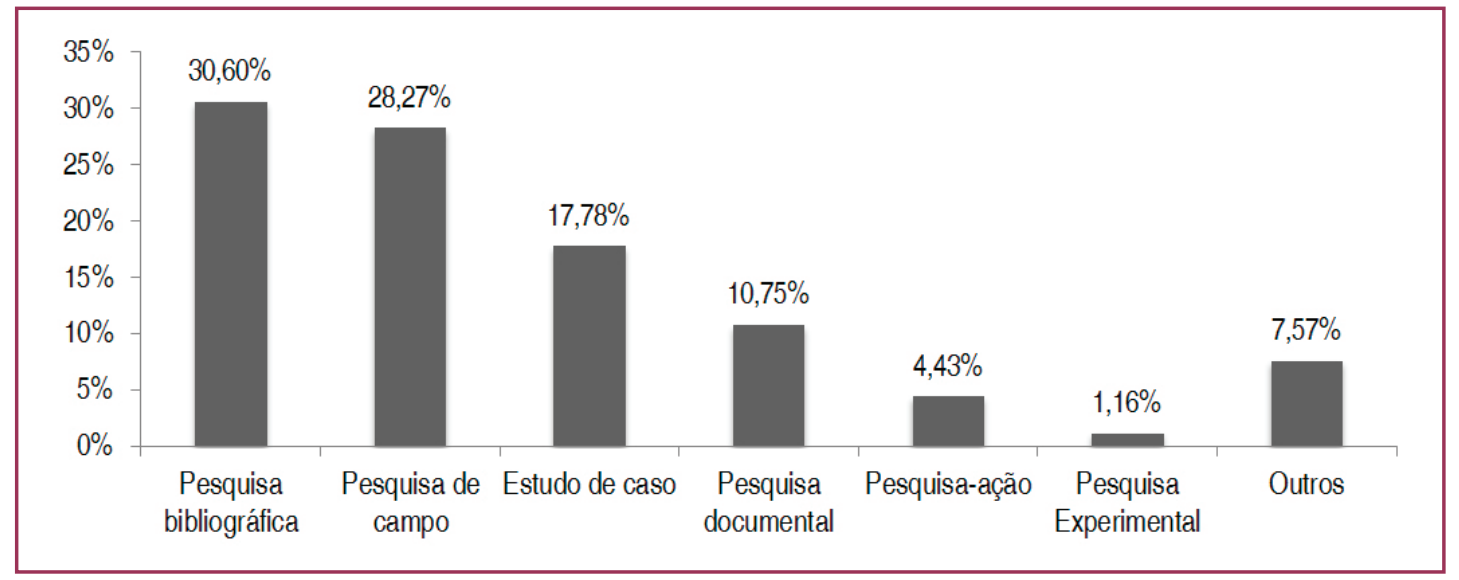

Fonte: Os autores

Buscou-se ainda analisar o comportamento da produção no que tange às temáticas enfocadas, conforme representado na Tabela 3. Considerando as três grandes categorias de análise, anteriormente assinaladas, observou-se que pesquisas ligadas à caracterização 
da Educação Física Escolar, representadas pela categoria "diagnóstico", obtiveram índice de $39,01 \%$, superando as temáticas de "intervenção", com 34,82\%, e "fundamentação", com $22,90 \%$.

Tabela 3. - Artigos sobre Educação Física Escolar categorizados por tema

\begin{tabular}{|c|c|c|c|}
\hline Categorias & $\mathrm{N}^{\circ}$ de artigos & $\%$ Categoria & $\%$ Total $=428$ \\
\hline \multicolumn{4}{|c|}{ FUNDAMENTAÇÃO } \\
\hline Sociofilosóficos & 33 & 33,67 & 7,71 \\
\hline Cineantropométricos/fisiológicos/treinamento & 2 & 2,04 & 0,47 \\
\hline Temas emergentes & 52 & 53,06 & 12,15 \\
\hline Esporte & 11 & 11,23 & 2,57 \\
\hline Total & 98 & 100 & 22,90 \\
\hline \multicolumn{4}{|c|}{ INTERVENÇÃO } \\
\hline Métodos de ensino & 10 & 6,71 & 2,34 \\
\hline Avaliação & 8 & 5,37 & 1,87 \\
\hline Currículo/organização & 24 & 16,11 & 5,61 \\
\hline Conteúdos & 28 & 18,79 & 6,54 \\
\hline Trato didático-pedagógico & 31 & 20,8 & 7,24 \\
\hline Formação/intervenção & 33 & 22,15 & 7,71 \\
\hline Cultura escolar & 15 & 10,07 & 3,51 \\
\hline Total & 149 & 100 & 34,82 \\
\hline \multicolumn{4}{|c|}{ DIAGNÓSTICO } \\
\hline Imaginário sobre a Educação Física & 12 & 7,19 & 2,80 \\
\hline Concepções (corpo, esporte, saúde) & 9 & 5,39 & 2,10 \\
\hline Histórias de vida & 22 & 13,17 & 5,14 \\
\hline Diagnósticos de contextos & 101 & 60,48 & 23,60 \\
\hline $\begin{array}{l}\text { Diagnósticos relativos ao desenvolvimento motor/ } \\
\text { cineantropometria }\end{array}$ & 23 & 13,77 & 5,37 \\
\hline Total & 167 & 100 & 39,01 \\
\hline \multicolumn{4}{|c|}{ OUTROS } \\
\hline Outros/diversos & 14 & 100 & 3,27 \\
\hline TOTAL & 428 & & 100 \\
\hline
\end{tabular}

\section{DESAFIOS E PERSPECTIVAS DA EDUCAÇÃO FÍSICA ESCOLAR}

A fim de discutir as principais tendências da pesquisa em Educação Física Escolar, partiuse dos aspectos que contextualizam a produção, como volume, financiamento, sexo dos autores e distribuição regional. Em seguida, tratou-se da abordagem metodológica e do enfoque temático.

\subsection{Perfil da produção}

O estudo demonstra que a Educação Física Escolar responde por apenas 16,20\% do conhecimento veiculado, no período de 2006 a 2012, no âmbito das oito revistas consultadas. Nível semelhante foi evidenciado por estudos correlatos (BRACHT et al., 2011, ANTUNES et al., 2005, ROSA; LETA, 2010, BETTI; FERRAZ; DANTAS, 2011, MORAIS; ASSUMPÇÃO, 
2012). Representando, portanto, uma das faces menos valorizadas das ciências do esporte, no Brasil, a pesquisa em Educação Física Escolar expressa, antes de tudo, uma lacuna no campo mais abrangente da produção.

Para além disso, a julgar pelos resultados de Antunes et al. (2005), o limitado desenvolvimento da pesquisa em Educação Física Escolar não parece ser uma característica exclusiva da realidade brasileira, fazendo parte também do cenário internacional. Tal conclusão levou Bracht et al. (2011) a considerarem que este dado é incompatível com o peso da Educação Física Escolar na área, sobretudo no âmbito da atuação profissional, estando ela sub-representada no conjunto da produção. Esse quadro estaria gerando, segundo a literatura, grave distanciamento entre universidade e escola. "Esse dado é preocupante, pois mostra um déficit de conhecimentos academicamente elaborados acerca da prática pedagógica na escola" (ANTUNES et al., 2005, p. 183).

Entre os motivos que explicam esse quadro se encontra o fato de a Educação Física Escolar não figurar como campo estratégico de interesse econômico e político, o que guarda relação com a tendência mundial que tem valorizado as tecnociências (Araújo, 1998 apud MANOEL; CARVALHO, 2011). A pesquisa e a sua transmissão são modificadas diante da transformação tecnológica na sociedade como um todo. "Pode-se prever que tudo o que no saber constituído não é traduzível será abandonado, e que a orientação das novas pesquisas se subordinará à condição de tradutibilidade dos resultados eventuais em linguagem de máquina." (LYOTARD, 2006, p. 4).

A condição da Educação Física Escolar no plano da "economia do conhecimento" repercute na distribuição desigual dos pesquisadores entre as áreas no âmbito da pós-graduação. De acordo com Manoel e Carvalho (2011), dos 298 docentes que estavam credenciados em programas de pós-graduação em Educação Física, no Brasil, em 2006, 60,70\% atuavam na subárea biodinâmica, 22,52\% na sociocultural e somente $17 \%$ na pedagógica. Em consonância, uma avaliação das teses defendidas nesses programas, de 1994 a 2008, verificou que, no universo de 333 trabalhos de doutorado, apenas 16, o que representa 6,30\%, se enquadravam na Educação Física Escolar (NASCIMENTO, 2010). Isso denota o pouco investimento da pós-graduação nas pesquisas em Educação Física Escolar. Considerando que a produção do conhecimento, no Brasil, é gerada predominantemente em programas de pós-graduação, conforme anteriormente destacado, há clara correlação entre o baixo volume da produção em Educação Física Escolar, o menor número de professores dessa linha de pesquisa que atuam nos programas e a pequena quantidade de teses defendidas com enfoque pedagógico.

Ao mesmo tempo, as atuais políticas de avaliação da pós-graduação em Educação Física adotam princípios fundamentados na área biodinâmica. De acordo com Rosa e Leta (2011, p. 9), a pós-graduação em Educação Física não contempla "[...] critérios adequados para avaliar o desempenho de pesquisadores que desenvolvem pesquisas e estudos em temáticas de EF com enfoques pedagógicos e socioculturais". Rigo, Ribeiro e Hallal (2011) acrescentam que tais políticas não abrangem a diversidade do campo e provocam, além do enfraquecimento da área sociopedagógica, a fragmentação da Educação Física.

Acrescente-se que as pesquisas em Educação Física Escolar se caracterizam pelo baixo nível de financiamento, considerando que apenas $11,21 \%$ dos artigos analisados obtiveram algum tipo de apoio na forma de capital/custeio ou bolsas. Na disputa pelo campo da Educação Física, o financiamento é uma chave importante, pois determina o grau de autonomia e a legitimação do conhecimento. Quanto maior a autonomia do campo, maior a resistência às pressões externas (BOURDIEU, 1990). 
Há correlação entre o status hierárquico que ocupa a área de Educação Física Escolar no campo das ciências do esporte e o baixo financiamento de pesquisas na área. Essa análise permite compreender prioridades das políticas de financiamento da produção do conhecimento e os desafios colocados aos pesquisadores baseados nas Ciências Humanas e Sociais. Os índices de fomento da Educação Física Escolar são emblemáticos para evidenciar o pouco interesse das agências.

À luz da teoria de campo, a Educação Física se caracteriza por disputas entre diferentes subáreas, que sustentam enfoques epistemológicos distintos para nortear a pesquisa. 0 "campo" é um espaço social onde ocorrem conflitos e se exerce dominação, a partir de regras particulares de organização e hierarquia. Por outro lado, "na luta pela produção e imposição da visão legítima do mundo social, os detentores de uma autoridade burocrática nunca obtêm um monopólio absoluto, mesmo quando se aliam à autoridade da ciência" (BOURDIEU, 1990, p. 165).

Por isso, apesar da situação discrepante em que se encontra a pesquisa em Educação Física Escolar no campo das ciências do esporte, cabe ressalvar que se observou crescimento de publicações, considerando o período pesquisado. A produção saiu de 7,30\% em 2006, para $18,20 \%$ em 2012. Com efeito, estudos que enfocam temas embasados em Ciências Humanas e Sociais têm espaço para evoluir, no Brasil. A despeito das origens da Educação Física se fundarem nas áreas médica e biológica:

[...] é sobre as áreas humanísticas, sociais e/ou culturais que tem buscado cada vez mais respaldo para melhor entender como se dão as relações entre a prática de atividade física e questões acerca do bem-estar, lazer, envelhecimento, de comportamentos sociais, etc. (ROSA; LETA, 2010, p. 131).

No plano internacional, Kirk (2010) também deposita um olhar otimista em direção ao futuro. Segundo ele, o surgimento de um programa de pesquisa pedagógica em Educação Física ocorreu na Europa, no final da década de 1960. Desde então, o objeto de pesquisa se expandiu proporcionalmente ao desenvolvimento da área. Ao longo da década de 2000, 0 autor identificou um cenário promissor, pois houve aumento de textos publicados em periódicos internacionais sobre pedagogia da Educação Física, de autoria europeia.

Sobre o perfil dos pesquisadores no que tange ao sexo, o estudo aponta que 55,84\% dos autores principais dos artigos analisados são do sexo masculino, contra 44,16\% do feminino. Outros trabalhos registraram um percentual semelhante, como 0 de Rosa e Leta (2010, p. 125), para quem "historicamente, a ciência sempre foi tida como uma atividade realizada por homens". Todavia, Leite et al. (2012), ao traçarem o perfil dos pesquisadores da área de Educação Física com bolsa produtividade no CNPq, revelaram que 75\% são homens, o que representa uma diferença mais significativa.

Observou-se, adicionalmente, na análise dos artigos, que a produção do conhecimento em Educação Física Escolar no Brasil está concentrada nas regiões Sudeste e Sul. Essa disparidade tem sido apontada, direta ou indiretamente, na literatura especializada em Educação Física (ROSA; LETA, 2010, MANOEL; CARVALHO, 2011, LEITE et al., 2012, BRANDL NETO; SILVA; MIRANDA, 2013). Esse aspecto limita ainda mais a abrangência da produção, pois as particularidades econômicas, sociais e culturais das demais regiões, que afetam as escolas e a Educação Física, não integram as análises desenvolvidas em outros contextos. Desse modo, o estudo das escolas das demais regiões do país, como é o caso do Norte, Nordeste e Centro- 
Oeste, pode se restringir a fontes não compatíveis com as características regionais particulares que marcam o extenso território nacional, gerando inconsistências.

\subsection{Tipos de pesquisa e temáticas enfocadas}

Os tipos de pesquisa encontrados nos estudos veiculados de 2006 a 2012 são bastante variados, pois abrangem a pesquisa bibliográfica (30,6\%), a pesquisa de campo $(28,27 \%)$, o estudo de caso $(17,28 \%)$ e a pesquisa documental $(10,74 \%)$, além de outros tipos menos frequentes. A maior parte tem em comum a abordagem qualitativa. Esse traço confirma a direção apontada por outros estudos, que evidenciaram equilíbrio entre os tipos de pesquisa. É o caso de Bracht et al. (2012, p. 30), para quem essa tendência "[...] parece acompanhar o amadurecimento da área". O comportamento da produção acompanha demandas por novos referenciais teórico-metodológicos nas Ciências Humanas e Sociais, apontadas pela Comissão Gulbenkian (PARA ABRIR..., 1996). Os atuais estudos reúnem um conjunto heterogêneo de perspectivas, de métodos, de técnicas de produção e de análise, englobando investigações do tipo etnográfico, pesquisa participante, estudo de caso, pesquisa-ação, até análise de discurso e de narrativas, estudo de memória, história de vida e história oral.

Quanto aos temas enfocados, o estudo indica que pesquisas ligadas à caracterização da Educação Física Escolar, representadas pela categoria "diagnóstico", obtiveram índice de $39,01 \%$, superando a categoria "intervenção" e "fundamentação". Antunes et al. (2005) avaliaram o período de 1999 a 2003 e identificaram resultado equivalente ao trabalho em tela (39,4\%). O trabalho de Betti, Ferraz e Dantas (2011), observou, de 2004 a 2008, um percentual ainda mais elevado para esse enfoque temático (59\%).

Antunes et al. (2005, p. 183) argumentaram que o alto índice de estudos que enfocaram a "caracterização" poderia "[...] indicar tão somente que essas pesquisas utilizam o contexto escolar - seus sujeitos, seu espaço, suas aulas - mas não teriam a preocupação de aproximar pesquisadores e professores". No entanto, deve-se levar em conta que os pesquisadores da Educação Física Escolar supõem que as variáveis de contexto interferem. Essas limitam ou dificultam os resultados do processo ensino-aprendizagem, os quais precisam ser identificados, o que pode explicar essa tendência.

Além disso, há significativo interesse dos estudos pelo processo ensino-aprendizagem da Educação Física na escola, representado pela categoria "intervenção", que atingiu 34,82\% do total. Estudos que delimitaram o período de revisão em anos anteriores ao deste trabalho, como $o$ de Antunes et al. (2005), que se localizou entre 1999 e 2003, e o de Betti, Ferraz e Dantas (2011), que delimitou a análise de artigos entre 2004 e 2008, evidenciaram índices inferiores para esse tema, $11,8 \%$ e $20 \%$, respectivamente. Portanto, há uma tendência de crescimento da pesquisa sobre didática na pesquisa em Educação Física Escolar, ao longo dos últimos anos.

O enfoque da didática se debruça sobre o peso dos fatores que marcam o cotidiano escolar, focalizando o currículo, as interações sociais na escola, a formatação do trabalho pedagógico, a aprendizagem dos conteúdos, as relações professor-aluno, a disciplina e avaliação. Essa tendência é uma resposta à reivindicação do campo profissional por subsídios para a prática pedagógica, o que pode ser indício da resposta ao atrofiamento das pesquisas em didática que a área experimentou nas últimas décadas (BRACHT; CAPARROZ, 2007, BETTI; 
FERRAZ; DANTAS, 2011). Esse enfoque relaciona-se, também, com mudanças no perfil das pesquisas em educação, que, conforme André (2001), abriram espaço para abordagens críticas e exame de situações do cotidiano escolar, sob a responsabilidade de pesquisadores ligados aos processos de ensino-aprendizagem, o que influi na política de avaliação de artigos no âmbito das revistas.

A categoria "fundamentação" foi evidenciada em $22,9 \%$ da produção examinada. Os registros sugerem uma tendência inversa da categoria "fundamentação" em relação à categoria "intervenção", pois a primeira se retrai enquanto a segunda se desenvolve. Os estudos de "fundamentação" marcaram de forma majoritária a origem do movimento renovador da Educação Física, ao longo da década de 1980 (BRACHT et al., 2011). Todavia, vêm perdendo espaço mais recentemente, o que supõe uma busca de equilíbrio entre os enfoques na área de Educação Física Escolar, conforme sugeriram Bracht et al. (2011) e Kirk (2010). De outra forma, Betti, Ferraz e Dantas (2011) argumentam que este traço pode ser melhor compreendido reconhecendo-se o deslocamento desse tipo de discussão para o contexto das políticas públicas, sobremaneira para a compreensão dos programas de Educação Física nos sistemas públicos de ensino. Em sua avaliação, tal movimento pode significar um avanço, pois atualmente é mais profícuo investigar a implantação desses programas, ou um alerta, no sentido de que houve um esgotamento do paradigma hegemônico, o que demanda a introdução de novas perspectivas teóricas.

Na cenário da produção europeia, o estudo de Kirk $(2010$, p. 11) ressaltou que a literatura enfoca atualmente com mais ênfase os processos de ensino-aprendizagem. Para 0 autor "[...] a preocupação com os professores e o ensino tem sido ultrapassada, em certa medida, pelo interesse nos alunos e na aprendizagem". E acrescenta que tem observado "[...] a consolidação do verdadeiro objeto da pesquisa educacional em Educação Física, que, em termos de língua inglesa, é a pedagogia". Confirmando essa tendência, Antunes et al. (2005), por meio da análise de periódicos internacionais, registraram índice de 45,2\% para estudos de processos de ensino-aprendizagem da Educação Física Escolar, que representa o maior entre os demais enfoques temáticos. Em contraste, os estudos sobre epistemologia representaram o menor percentual, com apenas $4 \%$.

Apesar de identificarmos um decrescente interesse da literatura nacional pelo enfoque da fundamentação, um traço particular da Educação Física Escolar brasileira é a presença de discussão epistemológica, diferentemente da produção internacional, que se caracteriza pela "[...] ausência de uma discussão epistemológica sobre a Educação Física e seus conteúdos" (RIBEIRO, 2011, p. 493).

Quanto aos subtemas enfocados, destacaram-se os "diagnósticos de contexto", na categoria "diagnóstico", representando cerca de $23,60 \%$ da produção total, seguido dos "temas emergentes", na categoria "fundamentação", atingindo $12,15 \%$ do conjunto de artigos analisados. Na categoria "intervenção", o tema mais privilegiado foi a "formação/intervenção", com $7,71 \%$. O destaque está em torno da subcategoria "temas emergentes", ligada às questões contemporâneas e atuais que afetam e/ou interferem na intervenção dos professores, entre as quais os megaeventos esportivos são uma expressão. Nota-se pequena concentração de estudos na subcategoria "cineantropométricos/fisiológicos/treinamento", na categoria "fundamentação". Outro tema pouco explorado é a "avaliação", na categoria "intervenção". E na categoria "diagnóstico" o tema "concepções (corpo, esporte, saúde)" foi menos valorizado 
na pesquisa em Educação Física Escolar. Esses temas representam, sobretudo, lacunas a ser preenchidas em ações futuras pelos pesquisadores do campo. Tais análises trazem em síntese as tendências da variedade temática que marca a produção em Educação Física Escolar de modo geral.

Cabe reiterar, por fim, que a revisão sistemática evidenciou um crescimento de publicações na área, no período. Esse fluxo sugere que a Educação Física Escolar se apresenta como uma agenda de pesquisa que poderá evoluir nos próximos anos. Para que isso ocorra, faz-se necessário fomentar políticas de pesquisa e pós-graduação que atendam às especificidades da área. Tais políticas devem considerar as discrepâncias regionais e a necessidade de financiamento, visando abrangência e consolidação de grupos de pesquisa, no país. Um programa de pesquisa em Educação Física Escolar não se justifica apenas pela relevância científica, mas sobretudo pela importância social, pois o acesso à educação de qualidade é um dos direitos fundamentais que caracterizam as sociedades modernas.

\section{REFERÊNCIAS}

ANDRÉ, Marli. Pesquisa em educação: buscando o rigor e a qualidade. Cadernos de Pesquisa, São Paulo, n. 113, p. 51- 64, jul. 2001.

ANTUNES, Fabia Helena Chiorboli et al. Um retrato da pesquisa brasileira em educação física escolar: 1999-2003. Motriz, Rio Claro, v. 11, n. 3, p. 179-184, set./dez. 2005.

BETTI, Mauro; FERRAZ, Osvaldo Luiz; DANTAS, Luiz Eduardo Pinto Basto Tourinho. Educação física escolar: estado da arte e definições futuras. Revista Brasileira de Educação Física e

Esportes, São Paulo, v. 25, p. 105-115, dez. 2011. Número especial.

BOURDIEU, Pierre. Coisas ditas. São Paulo: Brasiliense, 1990.

BRACHT, Valter et al. A educação física escolar como tema de produção de conhecimento nos periódicos da área no Brasil (1980-2010): parte I. Movimento, Porto Alegre, v. 17, n. 2, p. 11-34, abr.jun. 2011.

BRACHT, Valter et al. A educação física escolar como tema de produção de conhecimento nos periódicos da área no Brasil (1980-2010): parte II. Movimento, Porto Alegre, v. 18, n. 2, p. 11-37, abr.jun. 2012.

BRACHT, Valter. Educação física e ciência: cenas de um casamento (in)feliz. ljuí: UNIJUÍ, 1999.

BRACHT, Valter; CAPARROZ, Francisco Eduardo. O tempo e o lugar de uma didática da educação física. Revista Brasileira de Ciências do Esporte, Campinas, v. 28, n. 2, p. 21-37, jan. 2007.

BRANDL NETO, Inácio; SILVA, Sheila Aparecida Pereira dos Santos; MIRANDA, Maria Luiza de Jesus. A produção do conhecimento referente à temática metodologia de ensino na educação física escolar: um estudo sobre os procedimentos metodológicos. Pensar a Prática. Goiânia, v. 16, n. 3, p. 619-655, jul./set. 2013.

GIL, Antônio Carlos. Métodos e técnicas de pesquisa social. 6. ed. São Paulo: Atlas, 2008. 
GOMES, Isabelle Sena; CAMINHA, Iraquitam de Oliveira. Guia para estudo de revisão sistemática: uma opção para as ciências do movimento humano. Movimento, Porto Alegre, v. 20, n. 1, p. 395411, jan./mar. 2014.

GONZÁLEZ, Fernando Jaime; FENSTERSEIFER, Paulo Evaldo. Entre o "não mais" e o "ainda não": pensando saídas do não lugar da educação física escolar I. Cadernos de Formação RBCE, Florianópolis, v. 1, n. 1, p. 9-24, set. 2009.

KIRK, David. Why research matters: Current status and future trends in physical education pedagogy. Movimento, Porto Alegre, v. 16, n. 2, p. 11-43, abr./jun. 2010.

LEITE, Bárbara Daniane Gusmão Lopes et al. Profile of the researchers with productivity grants in the Brazilian National Research Council (CNPq) of the physical education area. Motricidade, Ribeira de Pena, v. 8, n. 3, p. 90-98, jul. 2012.

LUNA, Sérgio Vasconcelos de. Planejamento de pesquisa: uma introdução. São Paulo: Educ, 1997.

LYOTARD, Jean-François. A condição pós-moderna. 9. ed. Rio de Janeiro: José Olympio, 2006.

MANOEL; Edison de Jesus; CARVALHO, Yara Maria de. Pós-graduação na educação física brasileira: a atração (fatal) para a biodinâmica. Educação e Pesquisa, São Paulo, v. 37, n. 2, p. 389-406, maio/ago. 2011.

MAZZOTI, Alda Judith Alves; GEWANDSZNAJDER, Fernando. 0 método nas ciências naturais e sociais: pesquisa quantitativa e qualitativa. São Paulo: Pioneira, 1999.

MORAIS, Jacqueline de Fátima dos Santos; ASSUMPÇÃO, Renato Poubel de Sousa. Olhares para a produção bibliográfica sobre a educação física escolar: algumas reflexões a partir de um levantamento bibliográfico. Acta Scientiarum Education, Maringá, v. 34, n. 1, p. 121-128, jan./jun. 2012.

NASCIMENTO, Ana Claudia Silverio. Mapeamento temático das teses defendidas nos programas de pós-graduação em educação física no Brasil (1994-2008). 2010. 278 f. Tese (Doutorado em Ciência da Informação) - Escola de Comunicações e Artes, Universidade de São Paulo, São Paulo, 2010.

PARA ABRIR as ciências sociais. São Paulo: Cortez, 1996.

RIBEIRO, Carlos Henrique. Investigação pedagógica em educação física: análise das publicações em um periódico internacional. Motriz, Rio Claro, v. 17, n. 3, p. 486-497, jul./set. 2011.

RIGO, Luis Carlos; RIBEIRO, Gabriela M.; HALLAL, Pedro Curi. Unidade na diversidade: desafios para a Educação Física no século XXI. Revista Brasileira de Atividade Física \& Saúde, Pelotas, v. 16, n. 4, p. 339-345, out./dez. 2011.

ROSA, Suely; LETA, Jacqueline. Tendências atuais da pesquisa brasileira em educação física parte 1: uma análise a partir de periódicos nacionais. Revista Brasileira de Educação Física e Esporte, São Paulo, v. 24, n. 1, p. 121-134, jan./mar. 2010.

ROSA, Suely; LETA, Jacqueline. Tendências atuais da pesquisa brasileira em educação física parte 2: a heterogeneidade epistemológica nos programas de pós-graduação. Revista Brasileira de Educação Física e Esporte, São Paulo, v. 25, n. 1, p. 7-18, jan./mar. 2011. 
síntese criteriosa da evidência científica. Revista Brasileira de Fisioterapia, São Carlos, v. 11, n. 1, p. 83-89, jan./fev. 2007.

TANI, Go. Cinesiologia, educação física e esporte: ordem emanante do caos na estrutura acadêmica. Motus Corporis, Rio de Janeiro, v. 3, n. 2, p. 9-50, dez.1996. 